\title{
Sentinel lymph node mapping in endometrial cancer after 2020 ESGO-ESTRO-ESP consensus update: what will happen in the next few years?
}

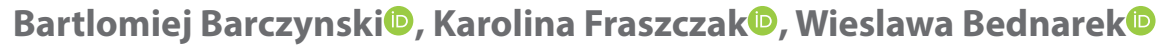 \\ Medical University in Lublin, Poland
}

\begin{abstract}
Comprehensive endometrial cancer staging requires mandatory lymph node status assessment. However, some randomized clinical studies show that full lymphadenectomy may have no therapeutic benefit in patients presented with early-stage disease. Sentinel lymph node mapping can be considered in patients at low to intermediate risk for nodal metastases and is an acceptable alternative to systemic lymphadenectomy for lymph node staging in FIGO stage I/II patients. Similarly, patients with serious comorbidities who might not tolerate a standard systemic lymphadenectomy may benefit from the procedure. Sentinel lymph node detection rates depend on cancer stage, histology, and technique used. The procedure is most performed with the use of radioactive technetium colloid $\left({ }^{99 \mathrm{~m} T c}\right)$ combined with a blue dye or indocyanine green. Recently, more interest is also paid to new nanoparticles including carbon, superparamagnetic iron oxide, and mannose tracer agents. Growing interest in sentinel lymph node mapping technique has led to design increasing number of research projects regarding various mapping approaches in different endometrial cancer populations. Much attention has been paid to a non-invasive sentinel lymph node mapping technique e.g., radiomics. This article reviews the latest research on sentinel lymph node mapping perspectives in endometrial cancer patients.
\end{abstract}

Key words: endometrial cancer; sentinel lymph node; indocyanine green

Ginekologia Polska 2022; 93, 4: 321-328

\section{INTRODUCTION}

Comprehensive endometrial cancer (EC) staging according to the most widely accepted method for cancer staging presented by The International Federation of Gynaecology and Obstetrics (FIGO) requires mandatory lymph node status assessment. Currently used preoperative imaging techniques including computed tomography and magnetic resonance are not sensitive enough to allow lymph node metastasis exclusion. Thus, pelvic and paraaortic lymphadenectomy remains the standard procedure for definite lymph nodes status assessment, and without lymphadenectomy even $90 \%$ of lymphatic metastases become undetected. Some authorities question the necessity of lymph nodes dissection in all cancer cases as ASTEC [1] and Benedetti-Panici [2] trials did not show any therapeutic benefit of lymphadenectomy in terms of overall, disease-specific, and recurrence-free survival in EC. Secondly, there is an increasing awareness of the long-term complications of the procedure, such as lymphoceles, lymphedemas and nerve injuries. The risk of lymph node metastases increases with depth of myometrial invasion and histologic differentiation grade. Therefore, all patients are stratified preoperatively into low-, intermediate-, and high-risk lymphatic spread groups requiring lymphadenectomy or not [3].

According to the 2016 European recommendations of ESMO-ESGO-ESTRO concerning EC diagnosis, treatment and follow-up, SLN biopsy [Sentinel Lymph Node] was considered as an experimental procedure, which should not be implemented in everyday clinical practice because of lack of strong supportive evidence for such management [3]. Last ESGO-ESTRO-ESP 2020 update confirmed that SLN biopsy procedure is an acceptable alternative to systemic

\footnotetext{
Corresponding author:

Bartlomiej Barczynski

Medical University in Lublin, 16 Staszica St, 20-081 Lublin, Poland

e-mail: bbarczynski@poczta.onet.pl
} 
lymphadenectomy for lymph node staging in stage I/II EC and it can be considered for staging purposes in patients with low- and intermediate-risk disease and even high-risk patients [4]. Similarly, National Comprehensive Cancer Network (NCCN) guidelines state that SLN mapping can be considered for surgical staging of apparent uterine-confined tumors, when there is no unequivocal metastasis demonstrated by the pre-surgical imaging techniques or no obvious extrauterine spread [5]. It seems to be most appropriate procedure for patients at low to intermediate risk for nodal metastases as well as patients with serious comorbidities who might not tolerate a standard systemic lymphadenectomy [6]. Interestingly, NCCN allows SLN mapping in both low and high risk histologies, including serous and clear-cell cancers [5, 7].

The rationale of SLN mapping procedure is to detect and excise selectively the first node(s) in a regional lymphatic basin drainage that receives lymph flow from the primary tumour. Pathological status of that SLN theoretically should predict the lymph node status of the patient. Another extremely important issue is the cooperation with pathologists, who should be familiar with an intraoperative SLN assessment and the ultrastaging technique and aware of the consequences of false-negative results, what is clearly underlined in both, ESGO-ESTRO-ESP and NCCN recommendations $[4,5]$. As far as the technical aspects are concerned, three injection sites can be considered: cervix, uterine fundus or peritumoral hysteroscopic injection. Cervical injection, due to its simplicity and accessibility is most commonly applied However, it is documented, that less paraaortic SLNs are detected with this technique, especially in tumors located in the upper third part of the uterus or fundus [8]. The recommended cervical injection sites include superficial (1-3 mm) and deep (10-20 mm) dye deliveries in two (9 and 3 o'clock) or four (9, 12, 3, 6 o'clock) locations. SLN mapping may be performed with the use of

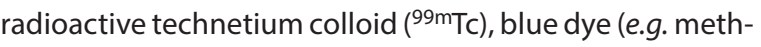
ylene blue), and indocyanine green (ICG) $[9,10]$. Recently, more interest is also paid to new nanoparticles including carbon, superparamagnetic iron oxide, and mannose tracer agents [11-13]. One of such new receptor-targeted lymphatic mapping agents is tilmanocept, a small-molecular size agent with high affinity for CD206 mannose receptor found in high concentrations on macrophages and dendritic cells $[13,14]$.

Growing interest in SLN mapping procedure has led to its use in many clinical centres. It is also recommended for all oncologic surgeons to follow new research trends and strategies in this area. The number of new projects presented on SLN mapping during recent time demonstrates high level of interest in SLN mapping among clinicians. Thus, we decided to perform a consistent review of the literature on this topic and present new trends and close future perspectives of SLN mapping in EC patients. For this purpose, we have searched Pubmed database using the following words/phrases: "endometrial cancer AND sentinel" to look for newest published reports on SLN mapping. All identified reviews/meta-analyses were manually searched for source data. Eventually, we have identified all new observational and interventional clinical trials registered in ClinicalTrials. gov - a database of privately and publicly funded clinical studies conducted around the world with "endometrial cancer" and "sentinel" keywords to look for current research trends in this field. In this short review, we focused only on high impact and well-designed cancer studies that influence everyday practice and identify new directions in endometrial cancer research.

\section{DETECTION RATES AND LOCALIZATIONS OF SLN}

SLN mapping has become a world-wide accepted standard of care in breast cancer and melanoma (and vulvar cancer). In most of oncologic centres, SLN detection rates exceed $90 \%$ using different techniques. Only high level of detection rate supports the application of the method in EC treatment protocols. Since SLN biopsy is increasingly and effectively used, the need for intra-operative assessment of myometrial invasion has become less important [4]. Recently published papers presented positive SLN mapping in majority of EC patients, with respective detection rates depending on cancer stage, histology, and technique used. In general, the most common SLN localizations include external iliac and obturator regions. Less common SLN localizations include internal iliac, common iliac, presacral, paraaortic, parametrial, and pararectal anatomic areas. Detailed results of studies presenting SLN localizations and detection rates are presented in Table 1.

Unfortunately, there is not much data on factors associated with mapping failures. Much effort still must be made to minimize the false negative detection rate. The objective of the study of lanieri et al, was to analyse factors associated with possible failure of bilateral SLN mapping with the use of ICG [24]. The authors evaluated different clinical (age, body mass index, menopausal status, previous history of pelvic surgery), pathological (tumor histology, diameter, clinical stage, lymphovascular space invasion status), and institutional (surgeon's experience and technical ability) factors that could be associated with unsuccessful SLN mapping procedure. Based on the multivariate analysis, the only significant factor associated with the success of bilateral SLN mapping was the surgeon's technical ability and experience [24]. SLN detection rates increase with number of procedures performed. Most experienced sites reach positive results close to $100 \%[25,26]$. In addition to factors 
Table 1. Detailed detection rates and SLN localizations in patients with endometrial cancer

\begin{tabular}{|c|c|c|c|c|}
\hline Author & $\begin{array}{l}\text { EC FIGO } \\
\text { stages }\end{array}$ & $\begin{array}{l}\text { Overall detection } \\
\text { rate }\end{array}$ & SLN localization & $\begin{array}{l}\text { Method } \\
\text { used }\end{array}$ \\
\hline $\begin{array}{l}\text { Stephens et al. (2020) } \\
\text { [15] }\end{array}$ & $|A-||| C 2$ & $85.7 \%$ & $\begin{array}{l}\text { External iliac }(69.1 \%) \text { Obturator }(25.1 \%) \\
\text { Internal iliac }(2.25 \%) \text { Common iliac (1.9\%) Presacral }(0.9 \%) \\
\text { Paraaortic }(0.4 \%) \text { Parametrial }(0.3 \%) \\
\text { Pararectal }(0.1 \%)\end{array}$ & $\begin{array}{l}\text { ICG } \\
\text { ISB }\end{array}$ \\
\hline $\begin{array}{l}\text { Tortorella et al. (2019) } \\
\text { [16] }\end{array}$ & $|-I I|$ & $93.3 \%$ & NS & ICG \\
\hline Ye et al. (2019) [17] & $|A-||| C 2$ & $93.1 \%$ & $\begin{array}{l}\text { External iliac }(53.3 \%) \\
\text { Obturator }(26.1 \%) \\
\text { Internal iliac }(16.2 \%) \\
\text { Common iliac }(2.8 \%) \\
\text { Paraaortic }(1.3 \%)\end{array}$ & ICG \\
\hline $\begin{array}{l}\text { Peiretti et al. (2020) } \\
\text { [18] }\end{array}$ & $|A-||| C 1$ & $93 \%$ & NS & ICG \\
\hline $\begin{array}{l}\text { Persson et al. (2019) } \\
\text { [19] }\end{array}$ & I-IV & $95 \%$ & $\begin{array}{l}\text { External iliac }(82 \%) \\
\text { Obturator }(63 \%) \\
\text { Presacral }(59 \%) \\
\text { Common iliac }(13 \%) \\
\text { No data regarding other localizations }\end{array}$ & ICG \\
\hline Wang et al. (2019) [20] & $|A-||| C 2$ & $86.7 \%$ & $\begin{array}{l}\text { External iliac (36\%) } \\
\text { Obturator }(35 \%) \\
\text { Internal iliac (16\%) } \\
\text { Common iliac (10\%) } \\
\text { Paraaortic (3\%) }\end{array}$ & ICG \\
\hline Zuo et al. (2019) [21] & $|-I I|$ & $\begin{array}{l}\text { Cervical injection } \\
100 \% \\
\text { Fundal injection } 92 \%\end{array}$ & $\begin{array}{l}\text { External iliac (44.5\%) } \\
\text { Obturator (22.5\%) } \\
\text { Internal iliac (20.6\%) } \\
\text { Common iliac }(9.5 \%) \\
\text { Paraaortic }(2.9 \%) \\
\text { Presacral }(0 \%)\end{array}$ & CNP \\
\hline Rossi et al. (2017) [22] & I-IV & $86 \%$ & $\begin{array}{l}\text { External iliac (38\%) } \\
\text { Obturator (25\%) Inframesenteric paraaortic (14\%) } \\
\text { Common iliac (8\%) Internal iliac (10\%) } \\
\text { Presacral (3\%) } \\
\text { Infrarenal paraaortic (1\%) } \\
\text { other (1\%) }\end{array}$ & ICG \\
\hline $\begin{array}{l}\text { Rozenholc et al. } \\
\text { (2019) [23] }\end{array}$ & $|A-I| \mid C$ & $\begin{array}{l}\text { ICG }(90.9 \%) \\
\text { MB (64.4\%) }\end{array}$ & NS & $\begin{array}{l}\text { ICG } \\
\text { MB }\end{array}$ \\
\hline
\end{tabular}

CNP — carbon nanoparticles; EC — endometrial cancer; FIGO — The International Federation of Gynaecology and Obstetrics; ICG — indocyanine green; ISB — isosulfan blue; $\mathrm{MB}$ — methylene blue; NS — not specified; SLN — sentinel lymph node

related to the technique and surgeon, successful mapping theoretically may also be affected by different patient/tumor factors, which could modify physiological lymphatic drainage, i.e., previously mentioned patient's body mass index, advanced age, previous pelvic surgeries/radiotherapy, tumor histology, some genital tract comorbidities (fibroids, endometriosis), although no reliable analyses in EC patients have been published so far. However, it was confirmed that successful bilateral SLN detection rate was associated with the specific method used, and ICG mapping seems to be the most effective method [27]. Although all available markers are acceptable options to use, the most recent experience of most sites indicates that ICG, with SLN visualisation using a near-infrared camera, is associated with the highest bilateral detection rates. Thus, ICG is rapidly becoming the marker of choice in SLN mapping.

\section{FUTURE PERSPECTIVES}

Growing interest in SLN mapping in EC supported by main gynaecologic oncology societies has led to a design of increasing number of clinical research regarding implementation of different SLN mapping procedures. Currently [access on 15 May 2021], there are 49 clinical trials registered in ClinicalTrials.gov identified using "endometrial cancer" and "sentinel" key words. 23 trials are actively recruiting subjects. Summarised descriptive characteristics of SLN mapping experiments is presented in Table 2. Most of the studies use ICG for the purpose of SLN mapping either alone 
Table 2. Summarized characteristics of currently registered clinical trials on sentinel lymph node mapping in endometrial cancer patients (data from ClinicalTrials.gov)

\begin{tabular}{|c|c|c|c|c|}
\hline Study Official Title & Study Type & $\begin{array}{l}\text { SLN Mapping } \\
\text { Method }\end{array}$ & Surgery Type & Inclusion Criteria in Regard to EC \\
\hline $\begin{array}{l}\text { Sentinel Node Mapping in High Risk Endometrial } \\
\text { Cancer (ALICE) }\end{array}$ & Interventional & ICG & MIS/laparotomy & $\begin{array}{l}\text { High risk EC (high grade } \\
\text { histologies or deep myometrial } \\
\text { invasion, FIGO IB-II) }\end{array}$ \\
\hline $\begin{array}{l}\text { Sentinel Node in Endometrial Cancer } \\
\text { (HYBRIDENDONOD) }\end{array}$ & Interventional & ICG, radiocolloid & MIS/laparotomy & $\begin{array}{l}\text { High risk EC (high grade } \\
\text { histologies or deep myometrial } \\
\text { invasion, } \geq \text { FIGO IB }\end{array}$ \\
\hline $\begin{array}{l}\text { Concurrent Use Lymphoseek \& Indocyanine Green } \\
\text { in Sentinel Lymph Node Detection in Endometrial } \\
\text { Cancer }\end{array}$ & Interventional & $\begin{array}{l}\text { ICG, mannose } \\
\text { nanoparticle } \\
\text { (Lymphoseek) }\end{array}$ & MIS & $\begin{array}{l}\text { Early stage (FIGO I-II) EC, each } \\
\text { histology }\end{array}$ \\
\hline $\begin{array}{l}\text { Use of the Sentinel Node Biopsy for Early } \\
\text { Endometrial Cancer (SNE) }\end{array}$ & Observational & NS & MIS/laparotomy & $\begin{array}{l}\text { Early stage (FIGO I-II) EC, each } \\
\text { histology }\end{array}$ \\
\hline $\begin{array}{l}\text { Prospective Study Comparing Three Injection Sites } \\
\text { to Detect Sentinel Lymph Nodes in Endometrial } \\
\text { Cancer (SENNAN) }\end{array}$ & Interventional & $\begin{array}{l}\mathrm{ICG} \text {, blue dye, } \\
\text { radiocolloid }\end{array}$ & MIS & $\begin{array}{l}\text { Early stage (FIGO I) EC, each } \\
\text { histology }\end{array}$ \\
\hline $\begin{array}{l}\text { Sentinel Lymph Node Sampling for Patients With } \\
\text { Middle-high Risk Endometrial Cancer Confined to } \\
\text { the Uterus }\end{array}$ & Interventional & NS & MIS/laparotomy & $\begin{array}{l}\text { Middle-high risk (FIGO I-II) EC, } \\
\text { each histology }\end{array}$ \\
\hline $\begin{array}{l}\text { Sentinel Node Detection in Endometrial Cancer: } \\
\text { A Consolidation Study on Detection Rates of } \\
\text { Metastatic Disease }\end{array}$ & Interventional & ICG & MIS & $\begin{array}{l}\text { Early stage (FIGO I-II) EC, each } \\
\text { histology }\end{array}$ \\
\hline $\begin{array}{l}\text { Tracers for Endometrial Cancer Sentinel Node } \\
\text { Labeling (TESLA-1) }\end{array}$ & Interventional & $\begin{array}{l}\mathrm{ICG} \text {, blue dye, } \\
\text { radiocolloid }\end{array}$ & MIS/laparotomy & $\begin{array}{l}\text { Intermediate and high-risk, early } \\
\text { stage (FIGO I-II) EC, each histology }\end{array}$ \\
\hline $\begin{array}{l}\text { Sentinel Node Biopsy in Endometrial Cancer } \\
\text { (ENDO-3) }\end{array}$ & Interventional & ICG & MIS & $\begin{array}{l}\text { Early stage (FIGO I) EC, each } \\
\text { histology }\end{array}$ \\
\hline $\begin{array}{l}\text { Accuracy of Sentinel Lymph Node Biopsy in Nodal } \\
\text { Staging of High Risk Endometrial Cancer (EndoSLN) }\end{array}$ & Interventional & ICG & MIS & $\begin{array}{l}\text { High risk EC (high grade } \\
\text { histologies or deep myometrial } \\
\text { invasion, FIGO IB-II) }\end{array}$ \\
\hline $\begin{array}{l}\text { Evaluation of Sentinel Node Policy in Early Stage } \\
\text { Endometrial Carcinomas at Intermediate and High } \\
\text { Risk of Recurrence (SENTIRAD) }\end{array}$ & Interventional & $\begin{array}{l}\mathrm{ICG} \text {, blue dye, } \\
\text { radiocolloid }\end{array}$ & MIS & $\begin{array}{l}\text { Middle-high and high risk EC } \\
\text { (FIGO I-II), each histology }\end{array}$ \\
\hline $\begin{array}{l}\text { To Assess and Compare the Performance Two } \\
\text { Approach for Sentinel Lymph Node (SNLD) Biopsy } \\
\text { for Endometrial Cancer }\end{array}$ & Observational & ICG & MIS & All FIGO stages EC, each histology \\
\hline $\begin{array}{l}\text { The Clinical Significance of Sentinel Lymph Node } \\
\text { Imaging Combined With Imaging Examination } \\
\text { in Pelvic and Peritoneal Lymphadenectomy for } \\
\text { Endometrial Carcinoma }\end{array}$ & Interventional & NS & MIS/laparotomy & All FIGO stages EC, each histology \\
\hline $\begin{array}{l}\text { Sentinel Node Mapping in Women With Cervical and } \\
\text { Endometrial Cancer (SENTIREC I) }\end{array}$ & Observational & ICG & MIS/laparotomy & $\begin{array}{l}\text { Low and intermediate riskEC, FIGOI, } \\
\text { endometrial adenocarcinoma }\end{array}$ \\
\hline $\begin{array}{l}\text { Observational Study of Women With Endometrial } \\
\text { Cancer Who Receive the Standard Treatment for } \\
\text { Their Disease }\end{array}$ & Observational & NS & MIS/laparotomy & $\begin{array}{l}\text { Low risk EC, FIGO I, endometrial } \\
\text { adenocarcinoma }\end{array}$ \\
\hline $\begin{array}{l}\text { Prediction of Recurrence Among Low Risk } \\
\text { Endometrial Cancer Patients }\end{array}$ & Observational & NS & MIS/laparotomy & $\begin{array}{l}\text { Low risk EC, FIGO I, endometrial } \\
\text { adenocarcinoma }\end{array}$ \\
\hline $\begin{array}{l}\text { Sentinel Node Mapping in Women With Endometrial } \\
\text { and Cervical Cancer (SENTIREC II) }\end{array}$ & Interventional & ICG & MIS & $\begin{array}{l}\text { High risk EC (high grade } \\
\text { histologies or deep myometrial } \\
\text { invasion, FIGO I) }\end{array}$ \\
\hline $\begin{array}{l}\text { PET/CT and Lymph Node Mapping in Finding } \\
\text { Lymph Node Metastasis in Patients With High-Risk } \\
\text { Endometrial Cancer }\end{array}$ & Interventional & ICG & MIS/laparotomy & $\begin{array}{l}\text { High risk EC (high grade } \\
\text { histologies or deep myometrial } \\
\text { invasion FIGO IB-II) }\end{array}$ \\
\hline $\begin{array}{l}\text { Modular Treatment With PMMR and Targeted } \\
\text { Compartmental Pelvic Lymphadenectomy } \\
\text { Followed by Therapeutic Pelvic and Paraaortic } \\
\text { Lymphadenectomy in Node Positive Disease for } \\
\text { Locoregional Control in Endometrial Cancer FIGO } \\
\text { Stages I-III (PMMR) }\end{array}$ & Observational & NS & Laparotomy & All FIGO stages, each histology \\
\hline
\end{tabular}


Table 2. (cont.) Summarized characteristics of currently registered clinical trials on sentinel lymph node mapping in endometrial cancer patients (data from ClinicalTrials.gov)

\begin{tabular}{|l|l|l|l|l|}
\hline Study Official Title & Study Type & $\begin{array}{l}\text { SLN Mapping } \\
\text { Method }\end{array}$ & Surgery Type & Inclusion Criteria in Regard to EC \\
\hline $\begin{array}{l}\text { The Role of Micrometastasis and Isolated } \\
\text { Tumor Cells in Endometrial and Cervical Cancer. } \\
\text { A Multicentre Study (ITCMicroUtCa) }\end{array}$ & Observational & NS & MIS/laparotomy & $\begin{array}{l}\text { Early stage (FIGO I-II) EC, each } \\
\text { histology }\end{array}$ \\
\hline $\begin{array}{l}\text { Evaluation of Indocyanine Green-guided Systematic } \\
\text { Pelvic Lymphadenectomy in Endometrial and } \\
\text { Cervical Cancer }\end{array}$ & Observational & ICG & MIS & All FIGO stages EC, each histology \\
\hline $\begin{array}{l}\text { Fluorescence for Sentinel Lymph Node Identification } \\
\text { in Cancer Surgery (GASVERT) }\end{array}$ & Interventional & ICG & MIS/laparotomy & All FIGO stages EC, each histology \\
\hline $\begin{array}{l}\text { Positron Lymphography Via Intracervical 18F-FDG } \\
\text { Injection for Pre-surgical Lymphatic Mapping } \\
\text { in Stage IB1 Cervical Cancer and High-grade } \\
\text { Endometrial Cancer }\end{array}$ & Interventional & $\begin{array}{l}\text { 18F-Fluorode- } \\
\text { oxyglucose }\end{array}$ & MIS/laparotomy & $\begin{array}{l}\text { High risk EC (high grade } \\
\text { histologies or deep myometrial } \\
\text { invasion, FIGO } \geq \text { IB) }\end{array}$ \\
\hline
\end{tabular}

EC — endometrial cancer; FIGO — The International Federation of Gynaecology and Obstetrics; ICG — indocyanine green; MIS — minimally invasive surgery; NS — not specified

or with blue dye/nanoparticles/radiocolloids. One study is planned to evaluate the diagnostic value of intracervical injection of $18 \mathrm{~F}$-Fluorodeoxyglucose during dynamic PET/CT scan performed on the day of surgery.

The currently registered trials may be grouped in three main categories in relation to EC patient characteristics. The first category of trials includes evaluation of benefits and risks of SLN mapping in all EC patients suitable for surgery, so the study designs include patients with all histologies and stages (5 studies). The second category of trials is focused on low/intermediate risk or FIGO I/II stage EC subjects ( 9 trials). The third group of remaining 9 trials is designed to assess SLN mapping technique in specific, less frequent high or high-intermediate risk groups of EC patients and they enrol only patients with high grade histologies and/or $\geq$ FIGO IB clinical stage. It must be mentioned that high-intermediate and high-risk patients may represent up to $41 \%$ of all EC patients [28]. More individualized surgical planning is critical in this group of patients as their risk of recurrence and overall mortality is higher. According to new ESGO-ESTRO-ESP recommendations SLN biopsy is an acceptable alternative to systematic lymphadenectomy for lymph node staging in FIGO I/II stage of the disease in this group of patients [4, 5].

In recent years, much attention regarding non-invasive SLN mapping has been paid to radiomics - novel approach to medical imaging techniques. Radiomic data has the potential to extract many different features from radiographic medical images using data-characterisation algorithms and artificial intelligence. It has been proved in various neoplasms that tumor characteristics in different imaging techniques (MRI, CT, PET) correlate with tumor molecular phenotype, genotype, and prognosis. As for now, there are only few studies that estimate the use anatomical or functional MRI/CT/PET radiomics aspects in SLN mapping.
Most research was performed on breast cancer patients and preoperative prediction of SLN metastasis [29, 30]. So far, there is only one report published on gynaecological cancer patients and it includes EC subjects [31]. One of the aims of the study of Crivellaro et al. [31] was to correlate radiomic characteristics extracted from primary tumor PET images and SLN status in women with apparent early-stage endometrial carcinoma. The authors concluded that PET radiomics features of the primary tumor seem promising for predicting the presence of nodal metastases not detected by visual radiologic analysis. Until the SLN procedure becomes more widespread, radiomics technique may help in stratifying the risk of nodal metastases, thus optimizing available resources [31].

Another technique tried in non-invasive SLN mapping is ultrasonography with the use of typical two-, and three-dimensional imaging, Doppler mode, M-mode, and elastography. The application of ultrasound in SLN mapping has been studied predominantly in breast and skin cancers, i.e., neoplasms that metastasize to superficial lymph nodes (axillary, and inguinal region). It is technically extremely difficult to visualize pelvic and paraaortic lymph nodes in usually overweight EC patients. Generally, routine preoperative ultrasound assessment of regional lymph nodes in cancer patients does not provide reliable nodal staging, because SLN tumor volume is too small to be reliably detected [32]. More reliable results are obtained by use of real-time tissue elastography [33] or contrast-enhanced ultrasound imaging [34]. Nam et al proved in swine melanoma model that such molecular lymphosonography with the use of targeted microbubbles labelled with P-selectin and $a_{v} \beta_{3}$-integrin antibodies can increase the specificity of metastatic SLN detection and provide a measure to quantify the extent of metastatic involvement [34]. There is no data in the literature 
regarding application of this method in gynaecological malignancies except for vulvar cancer, which metastasizes to relatively easy accessible superficially located inguinal and femoral lymph nodes.

It has to be noted that recent results of The Cancer Genome Atlas (TCGA) research will probably completely change our routine medical practice for certain types of tumors, including EC. Genome study classified EC into four categories: POLE ultramutated, microsatellite instability hypermutated, copy number low, and copy number high and let us further improve our understanding of the molecular characteristics of the endometrial malignancies [35]. As a result of TCGA findings, novel molecular classifier, the Proactive Molecular Risk Classifier for Endometrial Cancer (ProMisE), has been validated. This allows to assign patients to four different prognostic groups as surrogates of TCGA groups: mismatch repair deficient (surrogate of the microsatellite instable/hypermutated group), POLE mutated (surrogate of the ultramutated group), p53 mutated (surrogate of the copy number high group), and p53 wild type (surrogate of the copy-number low group, defined by the absence of the markers of the other three groups) [36]. This surrogate marker approach to the molecular-based classification has recently been demonstrated to be prognostically significant in low-, intermediate-, and high-risk endometrial carcinomas but may also be applicable to non-endometrioid tumors including serous, clear cell, undifferentiated carcinomas, and uterine carcinosarcomas [4]. Such novel molecular classification of ECs provides independent prognostic information beyond established clinicopathologic risk factors available at diagnosis and enables us to advance clinical management, including lymph nodes metastasis risk assessment. In regard to SLN mapping, ProMisE classifier provides stratification possibilities for future clinical trials, particularly identifying patients at low risk of lymphatic spread who are more likely to benefit from SLN mapping and not full lymphadenectomy. Current recommendations redefined EC prognostic risk groups implementing new molecular markers classification [4]. However, this implementation did not change SLN mapping procedures in patients planned for lymph node staging [4]. Most probably, future research will confirm utility of SLN mapping in all prognostic risk groups of EC patients except for excellent-outcome POLE-mutated carcinomas, in which any lymph node staging may not be necessary.

Finally, it must be clearly stated that the role of SLN mapping is constantly increasing as it offers an appropriate balance between the treatment-related morbidity of a complete lymph-node dissection and the risk of missing lymph-node involvement. The study of Imboden et al. [37] confirmed no differences between SLN and hysterectomy-only cohorts in intraoperative morbidity in low-risk EC patients and significant differences in perioperative blood loss, surgery time, and severity of complications in SLN vs full-lymphadenectomy cohorts. Similarly in a study of Accorsi et al., SLN biopsy did not increase the risk of intraoperative, and 30-day complications as well as did not cause lower limb lymphedema compared to simple hysterectomy cohort of EC patients [38]. Introduction of SLN biopsy also reduced operative time and improved perioperative surgical outcomes of robotic-assisted staging for early-stage EC without worsening the morbidity of hysterectomy alone [39]. Benefits of SLN technique regarding early and late ( $\leq 6$ months) lymphatic morbidity were confirmed not only in EC but also cervical cancer patients [40].

\section{CONCLUSIONS}

Sentinel lymph node mapping is a fairly feasible procedure which accurately predicts lymph node status in EC patients. Currently performed clinical trials predominantly favour the use of indocyanine green as a contrast dye agent for image-guided oncologic surgery. According to latest ESGO/ESTRO/ESP guidelines sentinel lymph node biopsy is as an alternative to lymph node dissection for lymph node staging and, if done according to state-of-art principles (including pathological ultrastaging), a negative sentinel node is accepted to confirm N0 status [4]. Full lymphadenectomy should be performed in patients with high-intermediate and high-risk disease [4]. Nevertheless, many gynaecologic oncologists remain unconvinced that systemic lymphadenectomy is mandatory, as SLN mapping results in better clinical outcome, e.g. decreased haemoglobin loss [41] and reduces the number of complications, e.g. lymphocele formation, which may affect up to $50 \%$ of systemic lymphadenectomy patients [42]. Thus, we are waiting for the results of currently performed clinical trials, especially addressing SLN mapping in high-intermediate and high-risk EC patients. Finally, what is most important, molecular ProMisE risk classifier will probably impact the comprehensiveness of surgical lymph node staging and determine new indications for SLN mapping in EC patients.

\section{Author contributions}

Conceptualization, methodology, formal analysis, data curation: B.B., K.F., W.B.; writing and original draft preparation, writing and review \& editing: B.B., W.B.; supervision:W.B. All authors have read and agreed to the published version of the manuscript.

\section{Funding}

The study was supported by Medical University of Lublin Grant No. 120/2020.

\section{Conflict of interests}

The authors declare no conflict of interests. 


\section{REFERENCES}

1. Kitchener H, Swart AMC, Qian Q, et al. Efficacy of systematic pelvic lymphadenectomy in endometrial cancer (MRC ASTEC trial): a randomised study. Lancet. 2009; 373(9658): 125-136, doi: 10.1016/s01406736(08)61766-3, indexed in Pubmed: 19070889.

2. Benedetti Panici P, Basile S, Maneschi F, et al. Systematic pelvic lymphadenectomy vs. no lymphadenectomy in early-stage endometrial carcinoma: randomized clinical trial. J Natl Cancer Inst. 2008; 100(23): 1707-1716, doi: 10.1093/jnci/djn397, indexed in Pubmed: 19033573.

3. Colombo N, Creutzberg C, Amant F, et al. ESMO-ESGO-ESTRO Endometrial Consensus Conference Working Group. ESMO-ESGO-ESTRO consensus conference on endometrial cancer: diagnosis, treatment and follow-up. Ann Oncol. 2016; 27(1): 16-41, doi: 10.1093/annonc/mdv484, indexed in Pubmed: 26634381.

4. Concin N, Matias-Guiu X, Vergote I, et al. ESGO/ESTRO/ESP guidelines for the management of patients with endometrial carcinoma. Int J Gynecol Cancer. 2021; 31(1): 12-39, doi: 10.1136/ijgc-2020-002230, indexed in Pubmed: 33397713.

5. NCCN Clinical Practice Guidelines in Oncology (NCCN Guidelines ${ }^{\circledast}$ ). Uterine neoplasms. Version 1.2021 - October 20, 2020. https://www. nccn.org/professionals/physician_gls/default.aspx\#uterine (15.05.2021).

6. Holloway RW, Abu-Rustum NR, Backes FJ, et al. Sentinel lymph node mapping and staging in endometrial cancer: A Society of Gynecologic Oncology literature review with consensus recommendations. Gynecol Oncol. 2017; 146(2): 405-415, doi: 10.1016/j.ygyno.2017.05.027, indexed in Pubmed: 28566221.

7. Soliman PT, Westin SN, Dioun S, et al. A prospective validation study of sentinel lymph node mapping for high-risk endometrial cancer. Gynecol Oncol. 2017; 146(2): 234-239, doi: 10.1016/j.ygyno.2017.05.016, indexed in Pubmed: 28528918.

8. Bogani G, Martinelli F, Ditto A, et al. Sentinel lymph node detection in endometrial cancer: does injection site make a difference? J Gynecol Oncol. 2016; 27(2): e23, doi: 10.3802/jgo.2016.27.e23, indexed in Pubmed: 26768786.

9. Buda A, Crivellaro C, Elisei F, et al. Impact of indocyanine green for sentinel lymph node mapping in early stage endometrial and cervical cancer: comparison with conventional radiotracer $(99 \mathrm{~m}) \mathrm{tc}$ and/or blue dye. Ann Surg Oncol. 2016; 23(7): 2183-2191, doi: 10.1245/s10434-0155022-1, indexed in Pubmed: 26714944.

10. Papadia A, Gasparri ML, Buda A, et al. Sentinel lymph node mapping in endometrial cancer: comparison of fluorescence dye with traditional radiocolloid and blue. J Cancer Res Clin Oncol. 2017; 143(10): 2039-2048, doi: 10.1007/s00432-017-2501-8, indexed in Pubmed: 28828528.

11. Zuo J, Wu LY, Cheng M, et al. Comparison study of laparoscopic sentinel lymph node mapping in endometrial carcinoma using carbon nanoparticles and lymphatic pathway verification. J Minim Invasive Gynecol. 2019; 26(6): 1125-1132, doi: 10.1016/j.jmig.2018.11.002, indexed in Pubmed: 30445188.

12. Taruno K, Kurita T, Kuwahata A, et al. Multicenter clinical trial on sentinel lymph node biopsy using superparamagnetic iron oxide nanoparticles and a novel handheld magnetic probe. J Surg Oncol. 2019; 120(8): 1391-1396, doi: 10.1002/jso.25747, indexed in Pubmed: 31667855.

13. Wallace AM, Hoh CK, Ellner SJ, et al. Lymphoseek: a molecular imaging agent for melanoma sentinel lymph node mapping. Ann Surg Oncol. 2007; 14(2): 913-921, doi: 10.1245/s10434-006-9099-4, indexed in Pubmed: 17146742.

14. Azad AK, Rajaram MVS, Metz WL, et al. $\mathrm{Y}$-Tilmanocept, a new radiopharmaceutical tracer for cancer sentinel lymph nodes, binds to the mannose receptor (CD206). J Immunol. 2015; 195(5): 2019-2029, doi: 10.4049/jimmunol.1402005, indexed in Pubmed: 26202986.

15. Stephens AJ, Kennard JA, Fitzsimmons CK, et al. Robotic sentinel lymph node (SLN) mapping in endometrial cancer: SLN symmetry and implications of mapping failure. Int J Gynecol Cancer. 2020; 30(3): 305-310, doi: 10.1136/ijgc-2019-000915, indexed in Pubmed: 31857439.

16. Tortorella L, Casarin J, Multinu F, et al. Sentinel lymph node biopsy with cervical injection of indocyanine green in apparent early-stage endometrial cancer: predictors of unsuccessful mapping. Gynecol Oncol. 2019; 155(1): 34-38, doi: 10.1016/j.ygyno.2019.08.008, indexed in Pubmed: 31402166.

17. Ye L, Li S, LuW, et al. A prospective study of sentinel lymph node mapping for endometrial cancer: is it effective in high-risk subtypes? Oncologist. 2019; 24(12): e1381-e1387, doi: 10.1634/theoncologist.2019-0113, indexed in Pubmed: 31270269.
18. Peiretti M, Candotti G, Buda A, et al. Feasibility of hand-assisted laparoscopic sentinel node biopsy in open endometrial cancer surgery. Minim Invasive Ther Allied Technol. 2020; 29(5): 299-303, doi: 10.1080/13645706.2019.1628063, indexed in Pubmed: 31187667.

19. Persson J, Salehi S, Bollino M, et al. Pelvic sentinel lymph node detection in high-risk endometrial cancer (shrec-trial) - the final step towards a paradigm shift in surgical staging. Eur J Cancer. 2019; 116: 77-85, doi: 10.1016/j.ejca.2019.04.025, indexed in Pubmed: 31181536.

20. Wang $\mathrm{T}, \mathrm{Hu} \mathrm{Y}, \mathrm{He} \mathrm{Ya}$, et al. A retrospective validation study of sentinel lymph node mapping for high-risk endometrial cancer. Arch Gynecol Obstet. 2019; 299(5): 1429-1435, doi: 10.1007/s00404-019-05085-0, indexed in Pubmed: 30747328.

21. Zuo J, Wu LY, Cheng M, et al. Comparison Study of Laparoscopic Sentinel Lymph Node Mapping in Endometrial Carcinoma Using Carbon Nanoparticles and Lymphatic Pathway Verification. J Minim Invasive Gynecol. 2019; 26(6): 1125-1132, doi: 10.1016/j.jmig.2018.11.002, indexed in Pubmed: 30445188.

22. Rossi E, Kowalski L, Scalici J, et al. A comparison of sentinel lymph node biopsy to lymphadenectomy for endometrial cancer staging (FIRES trial): a multicentre, prospective, cohort study. The Lancet Oncology. 2017; 18(3): 384-392, doi: 10.1016/s1470-2045(17)30068-2.

23. Rozenholc A, Samouelian V, Warkus T, et al. Green versus blue: Randomized controlled trial comparing indocyanine green with methylene blue for sentinel lymph node detection in endometrial cancer. Gynecol Oncol. 2019; 153(3): 500-504, doi: 10.1016/j.ygyno.2019.03.103, indexed in Pubmed: 30902369.

24. Ianieri MM, Puppo A, Novelli A, et al. Sentinel lymph node biopsy in the treatment of endometrial cancer: why we fail? Results of a prospective multicenter study on the factors associated with failure of node mapping with indocyanine green. Gynecol Obstet Invest. 2019; 84(4): 383-389, doi: 10.1159/000496699, indexed in Pubmed: 30661071.

25. Khoury-Collado F, Abu-Rustum NR. Lymphatic mapping in endometrial cancer: a literature review of current techniques and results. Int J Gynecol Cancer. 2008; 18(6): 1163-1168, doi: 10.1111/j.1525-1438.2007.01188.x, indexed in Pubmed: 18217960.

26. Abu-Rustum NR, Khoury-Collado F, Pandit-Taskar N, et al. Sentinel lymph node mapping for grade 1 endometrial cancer: is it the answer to the surgical staging dilemma? Gynecol Oncol. 2009; 113(2): 163-169, doi: 10.1016/j.ygyno.2009.01.003, indexed in Pubmed: 19232699.

27. Tanner EJ, Sinno AK, Stone RL, et al. Factors associated with successful bilateral sentinel lymph node mapping in endometrial cancer. Gynecol Oncol. 2015; 138(3):542-547, doi: 10.1016/j.ygyno.2015.06.024, indexed in Pubmed: 26095896.

28. Sozzi G, Uccella S, Berretta R, et al. Tumor Size, an Additional Risk Factor of Local Recurrence in Low-Risk Endometrial Cancer: A Large Multicentric Retrospective Study. Int J Gynecol Cancer. 2018; 28(4): 684-691, doi: 10.1097/IGC.0000000000001223, indexed in Pubmed: 29489475.

29. Liu J, Sun D, Chen L, et al. Radiomics analysis of dynamic contrast-enhanced magnetic resonance imaging for the prediction of sentinel lymph node metastasis in breast cancer. Front Oncol. 2019; 9: 980, doi: 10.3389/fonc.2019.00980, indexed in Pubmed: 31632912.

30. Liu C, Ding J, Spuhler K, et al. Preoperative prediction of sentinel lymph node metastasis in breast cancer by radiomic signatures from dynamic contrast-enhanced MRI. J Magn Reson Imaging. 2019; 49(1): 131-140, doi: 10.1002/jmri.26224, indexed in Pubmed: 30171822.

31. Crivellaro $C$, Landoni $C$, Elisei $F$, et al. Combining positron emission tomography/computed tomography, radiomics, and sentinel lymph node mapping for nodal staging of endometrial cancer patients. Int J Gynecol Cancer. 2020; 30(3): 378-382, doi: 10.1136/ijgc-2019-000945, indexed in Pubmed: 32079712.

32. Thompson JF, Haydu LE, Uren RF, et al. MSLT-II Trial Group. Preoperative ultrasound assessment of regional lymph nodes in melanoma patients does not provide reliable nodal staging: results from a large multicenter trial. Ann Surg. 2021; 273(4): 814-820, doi: 10.1097/SLA.0000000000003405, indexed in Pubmed: 31188198.

33. Tanaka T, Kamata M, Fukaya S, et al. Usefulness of real-time elastography for diagnosing lymph node metastasis of skin cancer: does elastography potentially eliminate the need for sentinel lymph node biopsy in squamous cell carcinoma? J Eur Acad Dermatol Venereol. 2020; 34(4): 754-761, doi: 10.1111/jdv.15955, indexed in Pubmed: 31520558.

34. Nam K, Stapp R, Liu JB, et al. Performance of molecular lymphosonography for detection and quantification of metastatic involvement in 
sentinel lymph nodes. J Ultrasound Med. 2019; 38(8): 2103-2110, doi: 10.1002/jum.14906, indexed in Pubmed: 30589454.

35. Kandoth C, Schultz N, Cherniack AD, et al. Cancer Genome Atlas Research Network. Integrated genomic characterization of endometrial carcinoma. Nature. 2013; 497(7447): 67-73, doi: 10.1038/nature12113, indexed in Pubmed: 23636398.

36. Talhouk A, Hoang LN, McConechy MK, et al. Molecular classification of endometrial carcinoma on diagnostic specimens is highly concordant with final hysterectomy: Earlier prognostic information to guide treatment. Gynecol Oncol. 2016; 143(1): 46-53, doi: 10.1016/j.ygyno.2016.07.090, indexed in Pubmed: 27421752.

37. Imboden S, Mereu L, Siegenthaler F, et al. Oncological safety and perioperative morbidity in low-risk endometrial cancer with sentinel lymph-node dissection. Eur J Surg Oncol. 2019; 45(9): 1638-1643, doi: 10.1016/j.ejso.2019.05.026, indexed in Pubmed: 31229377.

38. Accorsi GS, Paiva LL, Schmidt R, et al. Sentinel lymph node mapping vs systematic lymphadenectomy for endometrial cancer: surgical morbidity and lymphatic complications. J Minim Invasive Gynecol.
2020; 27(4): 938-945.e2, doi: 10.1016/j.jmig.2019.07.030, indexed in Pubmed: 31421249 .

39. Casarin J, Multinu F, Tortorella L, et al. Sentinel lymph node biopsy for robotic-assisted endometrial cancer staging: further improvement of perioperative outcomes. Int J Gynecol Cancer. 2020; 30(1): 41-47, doi: 10.1136/ijgc-2019-000672, indexed in Pubmed: 31780567.

40. Mathevet $P$, Lécuru F, Uzan $C$, et al. Senticol 2 group. Sentinel lymph node biopsy and morbidity outcomes in early cervical cancer: Results of a multicentre randomised trial (SENTICOL-2). Eur J Cancer. 2021; 148: 307-315, doi: 10.1016/j.ejca.2021.02.009, indexed in Pubmed: 33773275.

41. Januszek SM, Barnas E, Skret-Magierlo J, et al. Obesity as a risk factor of in-hospital outcomes in patients with endometrial cancer treated with laparoscopic surgical mode. Ginekol Pol. 2020; 91(10): 573-581, doi: 10.5603/GP.a2020.0099, indexed in Pubmed: 33184824.

42. Wrobel A, Winkler I, Rechberger T, et al. Does intraoperative application of TachoSil reduce the number of lymphoceles after pelvic lymphadenectomy? Ginekol Pol. 2021 [Epub ahead of print], doi: 10.5603/GP.a2021.0065, indexed in Pubmed: 33914319. 